This item was submitted to Loughborough's Research Repository by the author.

Items in Figshare are protected by copyright, with all rights reserved, unless otherwise indicated.

\title{
Mapping synergies and trade-offs between energy and the sustainable development goals
}

PLEASE CITE THE PUBLISHED VERSION

https://doi.org/10.1038/s41560-017-0036-5

\section{PUBLISHER}

(C) the Authors. Published by the Nature Publishing Group

\section{VERSION}

AM (Accepted Manuscript)

\section{PUBLISHER STATEMENT}

This work is made available according to the conditions of the Creative Commons Attribution-NonCommercialNoDerivatives 4.0 International (CC BY-NC-ND 4.0) licence. Full details of this licence are available at: https://creativecommons.org/licenses/by-nc-nd/4.0/

\section{LICENCE}

CC BY-NC-ND 4.0

\section{REPOSITORY RECORD}

Nerini, Francesco Fuso, Julia Tomei, Long Seng To, Iwona Bisaga, Priti Parikh, Mairi Black, Aiduan Borrion, et al.. 2019. "Mapping Synergies and Trade-offs Between Energy and the Sustainable Development Goals". figshare. https://hdl.handle.net/2134/27219. 
1 MAPPING SYNERGIES AND TRADE-OFFS BETWEEN ENERGY AND THE

2 SUSTAINABLE DEVELOPMENT GOALS

3

4

5

6

7

8

9

10

11

12

Francesco Fuso Nerini ${ }^{1,2}$; Julia Tomei ${ }^{3} * *$; Long Seng To ${ }^{4,5}$; Iwona Bisaga ${ }^{6}$; Priti Parikh ${ }^{6}$; Mairi Black $^{4}$; Aiduan Borrion ${ }^{6}$; Catalina Spataru ${ }^{1}$; Vanesa Castan-Broto ${ }^{7,8}$; Gabrial Anandarajah ${ }^{1}$; Ben Milligan $^{9 * * *}$; Yacob Mulugetta ${ }^{4}$

${ }^{1}$ UCL Energy Institute, University College London, 14 Upper Woburn Place, WC1H 0NN, London, UK

${ }^{2}$ Unit of Energy Systems Analysis (dESA), KTH Royal Institute of Technology, Brinellvägen 68 SE-100 44 Stockholm, Sweden

${ }^{3}$ Institute for Sustainable Resources (ISR), University College London, 14 Upper Woburn Place, WC1H 0NN, London, UK

${ }^{4}$ Department of Science, Technology, Engineering and Public Policy (UCL STEaPP), University College London, 2nd Floor, Boston House, 36-38 Fitzroy Square, London W1T 6EY, UK

${ }^{5}$ Department of Geography, Loughborough University, Leicestershire LE11 3TU, UK

${ }^{6}$ Department of Civil, Environmental and Geomatic Engineering (CEGE), Chadwick Building, University College London, WC1E6BT London, UK

${ }^{7}$ Development Planning Unit (DPU), University College London, 34 Tavistock Square, London WC1H 9EZ, UK

${ }^{8}$ Faculty of Social Sciences, ICOSS, University of Sheffield, 219 Portobello, S1 4DP, Sheffield, UK

${ }^{9}$ Faculty of Laws, University College London, Bidborough House, London WC1H 9BT, UK

* francesco.fusonerini@energy.kth.se,** j.tomei@ucl.ac.uk, *** b.milligan@ucl.ac.uk

\section{ABSTRACT}

The 2030 Agenda for Sustainable Development-including 17 interconnected Sustainable Development Goals (SDGs) and 169 Targets-is a global plan of action for people, planet and prosperity. SDG7 calls for action to ensure access to affordable, reliable, sustainable and modern energy for all. Here we characterise synergies and trade-offs between efforts to achieve SDG7, and delivery of the 2030 Agenda as a whole. We identify 113 Targets requiring actions to change energy systems, and published evidence of relationships between 143 Targets and efforts to achieve SDG7. Synergies and trade-offs exist in three key domains, where decisions about SDG7 affect humanity's ability to: (1) realise aspirations of greater welfare and wellbeing; (2) build physical and social infrastructures for sustainable development; and (3) achieve sustainable management of the natural environment. There is an urgent need to better organise, connect and extend this evidence, to help all actors work together to achieve sustainable development. 
41 On 5 September 2015, the 193 members states of the United Nations (UN) adopted a new Agenda for 42 Sustainable Development ${ }^{1}$. The 2030 Agenda succeeds the UN's Millennium Development Goals 43 (MDGs), and features 17 Sustainable Development Goals (SDGs) with 169 Targets, which UN 44 member states have committed to implement by 2030. Energy was not explicitly referred to in the 45 MDGs, and came to be referred to as the 'missing' MDG $^{2}$. During the operational period of the 46 MDGs and negotiation of the 2030 Agenda, it was increasingly recognised that energy underpins 47 economic and social development, without which it would not be possible to eliminate poverty. This 48 change in status ${ }^{3}$ made sustainable energy provision and access one of the central themes of the 2030

49 Agenda, whose preamble calls for 'universal access to affordable, reliable and sustainable energy' and 50 recognises that 'social and economic development depends of the sustainable management of our 51 planet's natural resources'. . SDG7 is accompanied by five Targets to be achieved by 2030: ensure 52 universal access to affordable, reliable and modern energy services (7.1); increase the share of 53 renewable energy in the global energy mix (7.2); double the global rate of improvement in energy 54 efficiency (7.3); enhance international cooperation to facilitate access to clean energy research and 55 technology (7.a), and promote investment in energy infrastructure and clean energy technology (7.b).

56 By understanding the complex links between the SDGs and their constituent Targets, researchers can 57 better support policymakers to think systematically about interactions between the different SDGs; 58 including how actions to achieve each Goal affect each other within and between sectors ${ }^{3}{ }^{4}$. Studies to 59 date ${ }^{4,5}$ have lacked a Target-level approach or have focused on only a few of the SDGs ${ }^{6}$. Here we 60 present a formative attempt by an interdisciplinary group of researchers to identify the full range of 61 Goals and Targets in the 2030 Agenda that call for changes in energy systems, and characterise 62 evidence of synergies or trade-offs between delivery of each of the 169 Targets and efforts focused on 63 pursuit of SDG7 and each of its constituent Targets. The purpose of this Perspective is not to provide 64 definitive answers. Instead we aim to lay a foundation for systematic (and context specific) 65 exploration of the interlinkages between each of the SDG Targets, in the context of decision-making 66 about development and the transformation of energy systems ${ }^{1}$.

\section{Interlinkages between energy systems and the 2030 Agenda}

68 Figure 1 explains the methods used to assess each of the 169 Targets in the 2030 Agenda, and their respective interlinkages with energy systems. These were designed to answer two questions: (A) Does the Target call for action in relation to energy systems? and (B) Is there published evidence of synergies or trade-offs between the Target, and decisions about energy systems in pursuit of SDG7. 'Energy systems' were defined broadly to include all components of anthropogenic and environmental systems related to the production, conversation, delivery and use of energy ${ }^{5}$. A systems perspective is crucial to understanding the practical complexity of energy provision and use, and facilitates effective intervention strategies ${ }^{6}$. Results of the assessment for each Target are reported in full in the supplementary material, and summarised in Figure 2. 


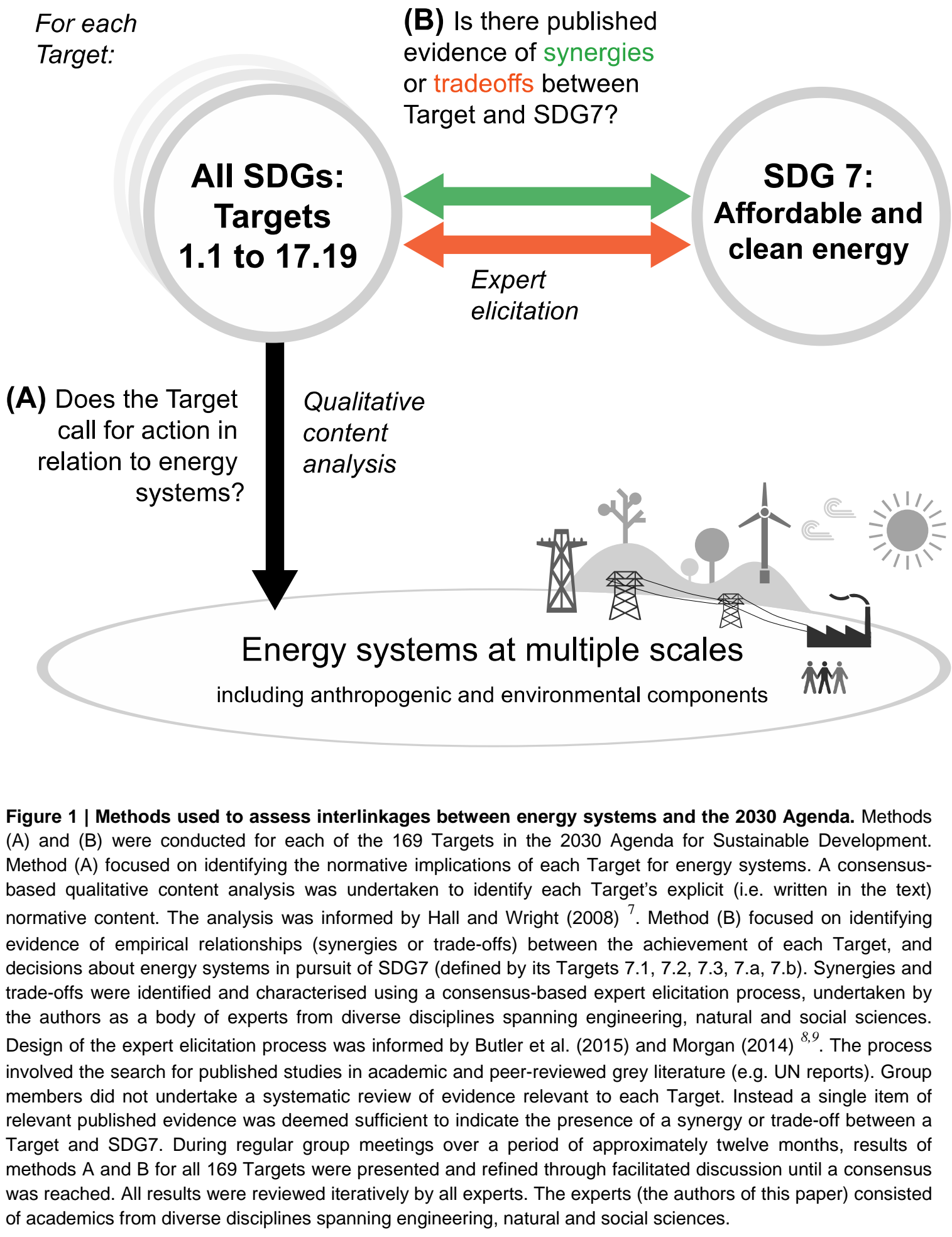

Figure 1 | Methods used to assess interlinkages between energy systems and the 2030 Agenda. Methods (A) and (B) were conducted for each of the 169 Targets in the 2030 Agenda for Sustainable Development. Method (A) focused on identifying the normative implications of each Target for energy systems. A consensusbased qualitative content analysis was undertaken to identify each Target's explicit (i.e. written in the text) normative content. The analysis was informed by Hall and Wright (2008) ${ }^{7}$. Method (B) focused on identifying evidence of empirical relationships (synergies or trade-offs) between the achievement of each Target, and decisions about energy systems in pursuit of SDG7 (defined by its Targets 7.1, 7.2, 7.3, 7.a, 7.b). Synergies and the authors as a body of experts from diverse disciplines spanning engineering, natural and social sciences. Design of the expert elicitation process was informed by Butler et al. (2015) and Morgan (2014) ${ }^{8,9}$. The process involved the search for published studies in academic and peer-reviewed grey literature (e.g. UN reports). Group members did not undertake a systematic review of evidence relevant to each Target. Instead a single item of Target and SDG7. During regular group meetings over a period of approximately twelve months, results of methods A and B for all 169 Targets were presented and refined through facilitated discussion until a consensus of academics from diverse disciplines spanning engineering, natural and social sciences. 
a.
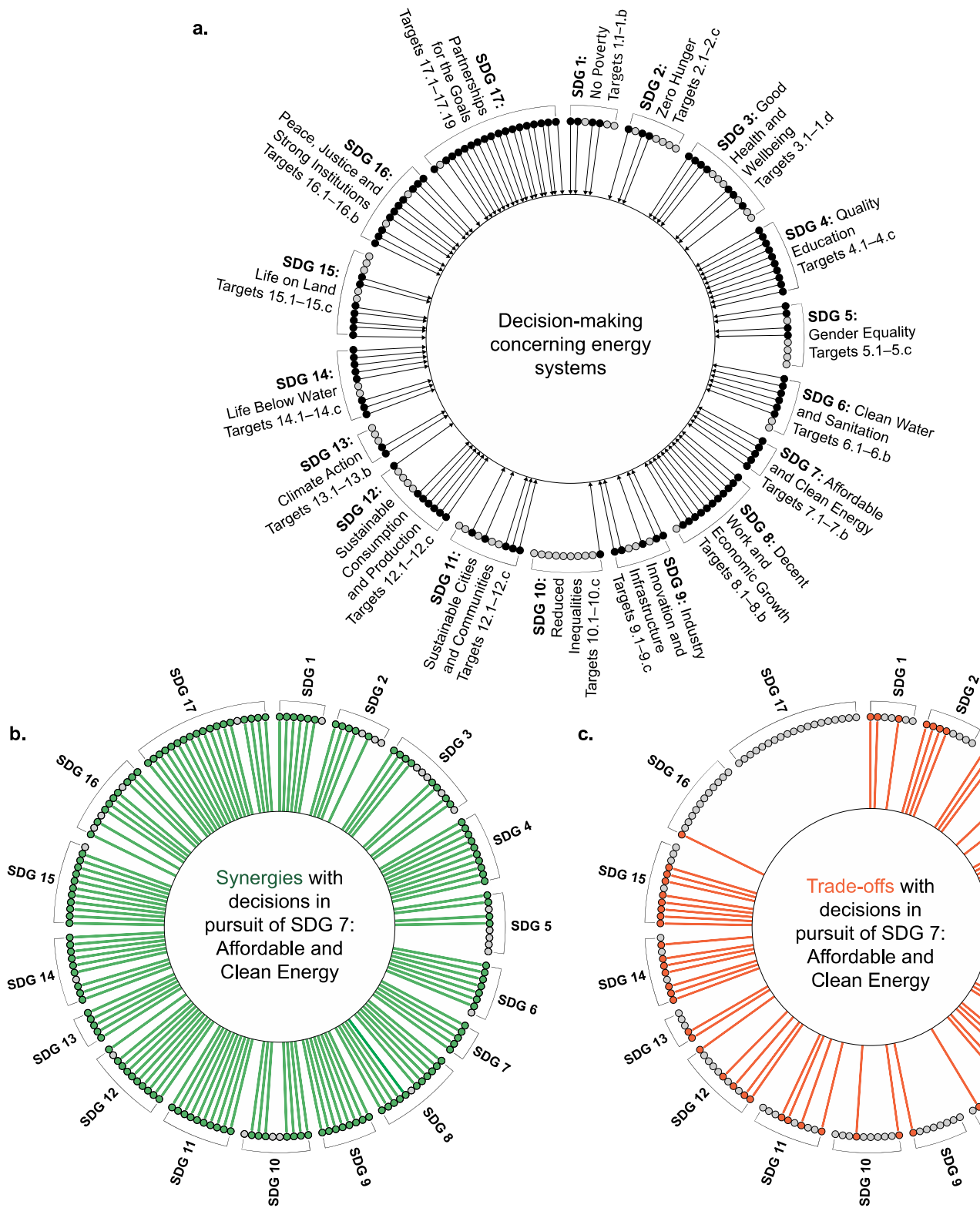

c.

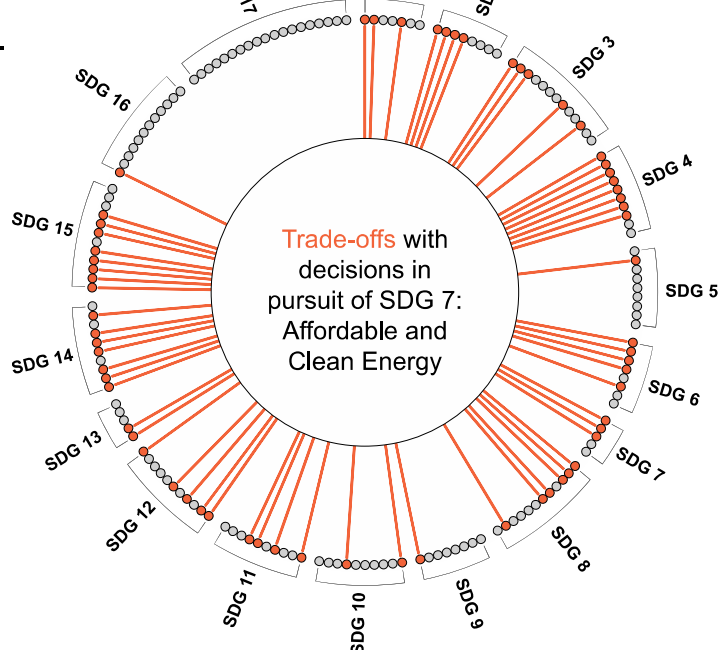

Figure 2 | Interlinkages between energy systems the SDGs and Targets. In a., b. and c. specific Targets recognised in the 2030 Agenda for Sustainable Development are grouped together under each associated SDG. Targets are ordered clockwise-e.g. Target 1.1 in each diagram is represented by the leftmost circle in the group associated with SDG1. a. Targets highlighted black (and indicated with black arrows) call for action in relation to energy systems. b. For Targets highlighted green (and indicated with green lines), we identified published evidence of synergies with decisions in pursuit of SDG7. c. For Targets highlighted orange (and indicated with orange lines), we identified published evidence of trade-offs with decisions in pursuit of SDG7. In b. and c., the absence of highlighting indicates the absence of identified evidence. This does not necessarily indicate the absence of a synergy or trade-off between the relevant Target and SDG7.

We found that 113 Targets ( 65\%) require actions to be taken concerning energy systems (A). Given the broad definition of energy systems mentioned above, these actions are diverse and include efforts to: address climate change (e.g. Target 13.2), reduce deaths from pollution (e.g. Target 3.9), and end certain human rights abuses (e.g. Target 8.7). This gives a strong indication of the substantial changes needed in global energy systems in order to deliver the SDGs. 
114 We also identified evidence of synergies or trade-offs between at least 143 Targets ( 85\%, spanning 115 all of the SDGs) and actions in pursuit of SDG7 (B). There are more than twice as many synergies 116 between SDG7 and other Targets, than trade-offs (143 synergies and 65 trade-offs). Nearly all tradeoffs relate to the tension between the need for rapid action to address key issues for human wellbeing planning needed to achieve efficient energy systems with a high integration of renewable energy. We did not attempt to map these comprehensively, and indicate only whether or not there was evidence of synergies or trade-offs. Our review of evidence suggested that there are likely to be multiple synergies and trade-offs within each Target, and that identification of these relationships is highly context specific. The coarse-grained synergies and trade-offs that we identified can be categorised into three broad domains, where decisions about energy systems affect humanity's ability to: first, realise individual and collective aspirations of greater welfare and wellbeing; second, build physical and social infrastructures for sustainable development; and finally, achieve sustainable management of the environment and natural resources. This is consistent with Goal-level analyses done in other contexts $^{10,11}$. The identified evidence concerning synergies and trade-offs (B) is summarised below, together with limited selected examples, and reported in full in the supplementary material.

\section{Aspirations of greater welfare and wellbeing}

The provision of affordable, reliable, sustainable and modern energy for all is vital for ensuring wellbeing. The contribution of energy to this domain is illustrated by this analysis, which identified 58 and 34 Targets with synergies and trade-offs respectively with SDG7 across all Goals.

Energy has a fundamental role to play in efforts to end poverty ${ }^{12}$ (SDG1). Provision of modern energy services (Target 7.1) will support the achievement of other Goals. For example, raising living standards through provision of basic services, including healthcare, education, water and sanitation (SDG2-4, 6-7, 9); improved household incomes (SDG8); and resilient rural and urban livelihoods (SDG1, 11). For instance, a focus on SDG4 (education) reveals the multiple synergies between wellbeing, energy and education at local, national and global levels. Target 4.2 requires that all girls and boys complete free, equitable and quality primary and secondary education. Achieving this Target depends on supply of electricity to schools, as well as to homes ${ }^{13}$. There is evidence that electricity access affects educational attainment ${ }^{14}$. Electricity is also vital for provision of information and communication technologies, which underpin adult education and global citizenship (Target 4.6, 4.7) ${ }^{15}$. This will be critical to eliminate local and global inequalities by providing access to information and technology, and empowering the social, economic and political inclusion of all (Target 10.2) ${ }^{16}$.

Realising greater welfare and wellbeing cannot be achieved without peaceful societies and equal access to justice (SDG16). There is great potential for justice-based approaches to aid energy decisions $^{17,18}$. Rather than just being an analytical concept, framing energy decisions in justice terms can help to elicit the relationship between individual and public values, map and resolve disputes, and give directional input to make better choices ${ }^{19}$. This is strongly recognised in the SDGs, for example, in terms of delivering improvements in governance of energy systems, including just institutions, strengthened rule of law, greater participation, transparency and accountability, access to information, and the reduction of corruption (Targets 9.c, 16.1, 16.3, 16.5, 16.7, 16.8, 16.10, 16.a, 16.b). For instance, development of many large-scale hydropower plants has been mired in social and political conflicts as a result of poor consultation with, and consideration of, livelihood conditions of affected local communities ${ }^{20}$. Similar impacts have been documented concerning the land used to produce 
158 biofuels ${ }^{21,22}$, and extraction of coal, gas and oil $^{23}$. These examples highlight the vital role of natural 159 resources in securing wellbeing (see below).

\section{Physical and social infrastructures}

161 Physical and social infrastructures link aspirations for wellbeing and welfare with the underpinning 162 natural resources ${ }^{10,24}$. There is published evidence of 109 Targets with synergies and 47 with trade163 offs between SDG7 and infrastructures. Energy is a core component of the physical and social

166 Existing energy infrastructures will need to be significantly upgraded to achieve SDG7 $7^{25,26}$. Nearly 1.2 167 billion people in the world lack access to electricity and $\sim 3$ billion people lack access to clean cooking 168 facilities ${ }^{26,27}$. A mix of locally appropriate centralised and decentralised energy infrastructures will be 169 needed to achieve universal energy access (Target 7.1) ${ }^{28}$. Infrastructures required for energy access 170 depend on access to financial services and markets (Target 9.3), knowledge (Target 9.5, 9.a), and 171 strong institutions and international cooperation (SDG17). Many Targets are underpinned by energy 172 access (Target 7.1) - energy is needed to power food systems ${ }^{29}$ (Target 2.1-2.4), medical facilities ${ }^{30}$ 173 (Target 3.1-3.4, 5.6), and water treatment and distributions systems (Target 6.1-6.3). Efficient water 174 infrastructure can also reduce energy usage ${ }^{26,31}$ (Target 6.4, 6.5). More broadly, energy in its various 175 forms is needed in cities (SDG11) where the spatial patterns influence the way we use energy, and 176 vice-versa ${ }^{32}$.

177

Energy contributes to the resilience of infrastructure, sustainable industrialisation (SDG9) and sustainable production and consumption (SDG12). For example, resilient and sustainable infrastructures (Target 9.1) require reliable energy systems with limited environmental impacts that mitigate adverse effects of climate change ${ }^{33}$. Climate change can affect the production of electricity from hydropower and thermal power plants in several regions of the world ${ }^{34}$. Achieving sustainable management and efficient use of natural resources (Target 12.2) will require changes to how energy systems use natural resources to minimise adverse impacts ${ }^{31}$.

\section{The environment and natural resources}

Natural environments are the foundation of human wellbeing and development - they are comprised of biotic and abiotic stocks of natural resources, which provide flows of valuable, and in some cases irreplaceable, goods in addition to ecosystem services ${ }^{35,36}$. Energy systems are underpinned by, and profoundly impact upon, these environmental stocks and flows ${ }^{37}$. There are 46 environment-related Targets with synergies, and 31 with trade-offs, with SDG7.

At a global scale, energy systems produce $\sim 60 \%$ of total anthropogenic emissions of greenhouse gases $^{38}$, and is consequently a core focus of urgent action to combat climate change and its impacts (SDG 13). Investment in low-carbon energy systems (Target 7.2, 7.a) will be fundamental to achieving the $2^{\circ} \mathrm{C} / 1.5^{\circ} \mathrm{C}$ mitigation goals of the 2015 Paris Agreement on Climate Change ${ }^{33}$. Reliable energy services underpinned by research, technology and infrastructure (Target 7.1, 7.a, 7.b) can contribute to climate change adaptation, natural hazard reduction and resilience (SDG3, 9, 13). Use of natural resources by globalised energy systems (e.g. for fuel, raw materials) has impacted on ecosystem services that underpin food and water security (SDG2,6), and human health ${ }^{36}$ (SDG3). The need to increase energy supply responding to growing demand, must be reconciled with the need to protect and restore critical ecosystems that support development in other sectors. This will depend on technology, behaviour and policy changes that dramatically decrease the natural resource-intensity of 
energy systems (Target 7.3, SDG 12) as part of broader efforts to decouple adverse environmental impacts from economic growth ${ }^{39}$ (Target 8.4).

There are complex trade-offs between the natural resource dependencies of energy, food and water systems, and environmental threats including biodiversity loss, climate change and localised air/ water pollution $^{40,31,41}$. Water quality and sanitation (SDG6, 14-15) are fundamental to social vulnerability (SDG1) and healthy lives (SDG3). Energy is needed to restore water-related ecosystems (Target 6.6, Goal 14-15), sustainably manage irrigation in food systems (Target 2.4), increase water efficiency (Target $6.4,9.4,11 . b)^{26,42}$, access and mobilise natural resources to end poverty (Target 1.4), and increase food production (Target 2.3, 2.4 ${ }^{43,44}$. Lack of access to modern energy services can drive ecosystem loss and degradation (Target 15.2) - for example any deforestation and forest degradation associated with use of fuelwood ${ }^{45,46}$.

214 Energy systems can have direct (e.g. local pollution, competition for space with energy infrastructure) 215 and indirect (e.g. ocean acidification, climate change ${ }^{47}$ ) impacts on conservation, restoration and enhancement of marine and terrestrial ecosystems and other natural resources (SDG9, 14-15) (8,49 $^{\text {. }}$ SDG15 is intertwined with the nature of energy transitions, especially where livelihoods are dependent on ecosystem goods and services ${ }^{50}$. Energy systems that fully account for these interdependencies including the multiple benefits and values of the environment (Target 15.9, 17.9) can minimise adverse impacts of energy use on ecosystems and biodiversity ${ }^{51}$ (Target 12.2).

\section{Empowering action to deliver the 2030 Agenda}

Our analysis highlights how energy systems are a foundation of social and economic development, and affect delivery of outcomes across all SDGs. It is also not possible to deliver SDG7 - ensuring access to affordable, reliable, sustainable and modern energy for all - without understanding how energy systems affect and depend on wellbeing, infrastructure and the environment. The SDGs represent a new framework for examining these linkages and making decisions that balance them effectively. Our analysis represents a first step towards mapping relationships between energy systems, SDG7, and other Goals in the 2030 Agenda. It reveals the tremendous complexity of links between energy systems and wellbeing, infrastructure and the environment, which means that SDG7 cannot be achieved in sectoral isolation. We have shown that all SDGs and $\sim 65 \%$ of Targets require action to change energy systems.

234 We found evidence of synergies between 143 Targets and efforts to achieve SDG7, meaning that $\sim 85 \%$ of 2030 Agenda Targets are mutually reinforcing with SDG7. We also found evidence of tradeoffs between SDG7 and 35\% of the 2030 Agenda Targets. Many of these trade-offs relate to tensions between the need to rapidly expand access to basic services, and the need for efficient energy systems underpinned by renewable resources. These synergies and trade-offs will manifest differently in different settings, and the impacts for different social groups will need to be understood and accommodated. Considerations of rights, justice and equity must be integrated into the exploration of solutions for these complex energy dilemmas, ${ }^{19}$ to ensure we leave no one behind. Every Target counts, and no single Target should be overlooked in efforts to achieve SDG7. This will be a challenging task which will require collaboration between diverse actors across every domain.

\section{Implications for researchers}

245 For the research community, this task depends on transdisciplinary collaboration. This includes understanding the interactions between disciplines and diverse actors, and will require generation of, and access to, data and knowledge on energy and other sectors. Current knowledge concerning energy and sustainable development is isolated in many different institutions, locations and disciplines. The 
isolation is compounded by the fact that many people, in all countries, cannot or have not been empowered with skills needed to access this knowledge. To address this, the evidence on the linkages between energy systems, SDG7 and other Goals need to be organised and connected in a manner that informs and enables efforts to achieve the 2030 Agenda. Our analysis provides a useful framework for researchers and decision-makers to design and evaluate specific interventions in energy systems to achieve sustainable development. However, this needs to be done as an inclusive, collaborative and open initiative to link energy research back to specific Targets and Goals. Such collaboration is already taking place in other contexts, for example the Future Earth Knowledge Action Networks ${ }^{52}$.

Implications for decision-makers

For decision makers in public and private sectors, the 2030 Agenda highlights that wellbeing for all can only be realised by transforming vertical silos and current modes of resource use, and by paying proper attention to supporting infrastructures and the natural environment. To this end the complexity of interrelationships between SDG7 and other Goals challenges conventional structures and processes of decision-making in government and private entities. Decision makers can no longer think in silos, and will need to find ways of widening participation, creating collective ownership and building consensus. In practice, this will require a transformation in the structure of decision-making, including the integration of vertical and horizontal planning and a long-term perspective. This requires strong local and national visions that are sensitive to the need for global collaboration. Given that energy cuts across all SDGs, structured analyses such as the one presented here can help to ensure that actions to achieve SDG7 are compatible with local and national development priorities. In so doing, this type of analysis can help the design of policies that balance synergies and trade-offs across wellbeing, infrastructure and environment in specific settings.

271 Policy makers responsible for energy matters need to collaborate with colleagues in other portfolios 272 and vice-versa, and establish governance structures to enable and sustain such coordination. However, 273 the principle of working across sectors and disciplines does not come naturally as it challenges entrenched institutional and sectoral behaviours. Cross-sectoral conversations on these institutional challenges will help advance this integrated agenda. The approach presented here can help policy makers to review existing institutional architectures and sector-specific policies to determine whether they are compatible with delivery of the 2030 Agenda. International organisations, including development banks, have an important role to play by coordinating action, measuring progress, facilitating dialogue and providing finance ${ }^{45,53}$.

A call to action

281 Finally, each and every actor has a role to play to achieve sustainable development. For SDG7, there

282 is a tension between the need for action required to rapidly address urgent energy-related issues (e.g. 283 energy access), and the careful planning of complex energy systems which underpin long-term development outcomes. Balancing these needs will require new skills and capacity to build countryspecific and regional strategies. A more level playing field across actors and countries is required recognising that developing countries will need to build further capabilities around production, transmission, distribution and energy consumption. The research community can help build and provide the knowledge and capacity needed for other actors to operationalise SDG7 at national and sub-national levels. This includes developing and sharing flexible and appropriate tools. We envisage that applications of this approach to specific contexts can help identify key gaps in knowledgewhere collaboration between actors may help to address knowledge gaps and to structure action. A strategy that brings all actors together to craft appropriate policies that balance synergies and tradeoffs between SDG7 and the other Goals is essential. 
294 We encourage all actors to contribute to this discussion - by enriching our analysis with additional 295 evidence, and applying it to energy policies, programmes and projects so that their design accounts for 296 the complexity of the 2030 Agenda. Our analysis is intended to serve as a basis for dialogue and 297 iterative action to deliver SDG7, in a manner that realises wellbeing through provision of key 298 infrastructures, and conservation, restoration and enhancement of the natural environment and its 299 resources.

\section{Author Contributions:}

301 F.F.N. coordinated inputs from other authors, designed and contributed to the expert elicitation 302 process, and wrote the paper. J.T., B.M., L.S.T. and Y.M. designed and contributed to the expert 303 elicitation process, and wrote the paper. I.B., P.P., M.B., A.B., C.S., V.C.B. and G.A. contributed to 304 the peer-reviewed expert elicitation process, and writing sections of the paper.

\section{Acknowledgements}

307 The authors would like to thank Xavier Lemaire, Michelle Shipworth, Omotola Adeoye and Carlos 308 Huggins for their helpful comments. Also thanks to the Energy and Development group at UCL 309 which provided a platform for this work to be realised.

\section{Competing interests}

312 The authors declare no competing financial interests. 
1. UN General Assembly (UNGA). Transforming our world: the 2030 Agenda for Sustainable

2. Brew-Hammond, A. Energy: The Missing Millennium Development Goal. in Energy for Development 35-43 (Springer Netherlands, 2012). doi:10.1007/978-94-007-4162-1_3

3. Lu, Y., Nakicenovic, N., Visbeck, M. \& Stevance, A.-S. Policy: Five priorities for the UN Sustainable Development Goals. Nature 520, 432-433 (2015).

4. Nilsson, M., Griggs, D. \& Visback, M. Map the interactions between Sustainable Development Goals. Nature 534, 320-322 (2016).

5. IRENA. REthinking Energy 2017: Accelerating the global energy transformation. International. International Renewable Energy Agency (2017). Available at: http://www.irena.org/DocumentDownloads/Publications/IRENA_REthinking_Energy_2017.p df

6. International Council for Science. A guide to SDG interactions: from science to implementation. (2017). Available at: https://www.icsu.org/publications/a-guide-to-sdginteractions-from-science-to-implementation

7. Hall, M. A. \& Wright, R. F. Systematic content analysis of judicial opinions. California Law Review 96, 63-122 (2008).

8. Butler, A. J., Thomas, M. K. \& Pintar, K. D. M. Systematic Review of Expert Elicitation Methods as a Tool for Source Attribution of Enteric Illness. Foodborne Pathog. Dis. 12, 367 382 (2015).

9. Morgan, M. G. Use (and abuse) of expert elicitation in support of decision making for public policy. Proc. Natl. Acad. Sci. U. S. A. 111, 7176-84 (2014).

10. Waage, J. et al. Governing the UN sustainable development goals: interactions, infrastructures, and institutions. Lancet. Glob. Heal. 3, e251-2 (2015).

11. Africa Progress Panel. Lights Power Action. Electrifying Africa. (2017). Available at: http://www.africaprogresspanel.org/wpcontent/uploads/2017/03/APP_Lights_Power_Action_Web_PDF.pdf

12. Practical Action. Poor people's energy outlook 2014. (2014). Available at: https://infohub.practicalaction.org/oknowledge/bitstream/11283/556929/9/PPEO_English_201 4_LowRes_New.pdf

13. Dornan, M. Access to electricity in Small Island Developing States of the Pacific: Issues and challenges. Renew. Sustain. Energy Rev. 31, 726-735 (2014).

14. UNDESA. Electricity and education: The benefits, barriers, and recommendations for achieving the electrification of primary and secondary schools. (2014). Available at: https://sustainabledevelopment.un.org/content/documents/1608Electricity\%20and\%20Educati on.pdf

15. Sovacool, B. K. \& Ryan, S. E. The geography of energy and education: Leaders, laggards, and lessons for achieving primary and secondary school electrification. Renew. Sustain. Energy Rev. 58, 107-123 (2016).

16. Chaurey, A. \& Kandpal, T. C. Assessment and evaluation of PV based decentralized rural electrification: An overview. Renewable and Sustainable Energy Reviews 14, 2266-2278 (2010).

17. Jenkins, K., McCauley, D., Heffron, R., Stephan, H. \& Rehner, R. Energy justice: A conceptual review. Energy Res. Soc. Sci. 11, 174-182 (2016). 
402

403

404

18. Sovacool, B. K., Heffron, R. J., McCauley, D. \& Goldthau, A. Energy decisions reframed as justice and ethical concerns. Nat. Energy 1, 16024 (2016).

19. Sovacool, B. K. \& Dworkin, M. H. Global Energy Justice: Problems, Principles, and Practices. Cambridge University Press (2014). doi:10.1017/CBO9781107323605

20. Tilt, B., Braun, Y. \& He, D. Social impacts of large dam projects: A comparison of international case studies and implications for best practice. J. Environ. Manage. 90, S249S257 (2009).

21. Hunsberger, C., Bolwig, S., Corbera, E. \& Creutzig, F. Livelihood impacts of biofuel crop production: Implications for governance. Geoforum 54, 248-260 (2014).

22. Tomei, J. The sustainability of sugarcane-ethanol systems in Guatemala: Land, labour and law. Biomass and Bioenergy 82, 94-100 (2015).

23. Kirshner, J. \& Power, M. Mining and extractive urbanism: Postdevelopment in a mozambican boomtown. Geoforum 61, 67-78 (2015).

24. Parikh, P., Chaturvedi, S. \& George, G. Empowering change: The effects of energy provision on individual aspirations in slum communities. Energy Policy 50, 477-485 (2012).

25. Mentis, D. et al. Lighting the World: The first global application of an open source, spatial electrification tool (ONSSET), with a focus on Sub-Saharan Africa. Environ. Res. Lett. 12, (2017).

26. IEA. World Energy Outlook 2016. (2016).

27. World Health Organization. Clean Household Energy for Health, Sustainable Development, and Wellbeing of Women and Children. WHO Guidelines (2016). http://apps.who.int/iris/bitstream/10665/204717/1/9789241565233_eng.pdf?ua=1

28. Fuso Nerini, F. et al. A cost comparison of technology approaches for improving access to electricity services. Energy 95, 255-265 (2016).

29. Ringler, C. et al. Global linkages among energy, food and water: an economic assessment. $J$. Environ. Stud. Sci. 6, 161-171 (2016).

30. World Health Organisation and World Bank. Modern Energy Services for Health Facilities in Resource-Constrained Settings. (2015). Available at: http://apps.who.int/iris/bitstream/10665/156847/1/9789241507646_eng.pdf

31. Howells, M. et al. Integrated analysis of climate change, land-use, energy and water strategies. Nat. Clim. Chang. 3, 621-626 (2013).

32. Broto, V. C. Energy landscapes and urban trajectories towards sustainability. Energy Policy 108, 755-764 (2017).

33. IEA \& IRENA. Perspectives for the Energy Transition. Investment Needs for a Low-Carbon Energy System. (2017). Available at: https://www.irena.org/DocumentDownloads/Publications/Perspectives_for_the_Energy_Transi tion_2017.pdf

34. van Vliet, M. T. H., Wiberg, D., Leduc, S. \& Riahi, K. Power-generation system vulnerability and adaptation to changes in climate and water resources. Nat. Clim. Chang. 6, 375-380 (2016).

35. Díaz, S. et al. The IPBES Conceptual Framework - connecting nature and people. Curr. Opin. Environ. Sustain. 14, 1-16 (2015).

36. UNEP. Environment for the future we want. GEO5. Global Environment Outlook. (2012). doi:10.2307/2807995. Available at: http://www.unep.org/geo/sites/unep.org.geo/files/documents/geo5_report_full_en_0.pdf

37. United Nations Development Programme. World Energy Assessment. Energy and the 
challenge of Sustainability. World Energy Assessment (2000). Available at: http://www.undp.org/content/undp/en/home/librarypage/environmentenergy/sustainable_energy/world_energy_assessmentenergyandthechallengeofsustainability.ht $\mathrm{ml}$

38. IPCC. IPCC Fifth Assessment Report. (2014). Available at: https://www.ipcc.ch/report/ar5/

39. UNEP. Resource Efficiency: Potential and Economic Implications. (2017). Available at: http://wedocs.unep.org//handle/20.500.11822/7585

40. International Energy Agency. Energy and Air Pollution. World Energy Outlook - Special Report (2016). Available at:

https://www.iea.org/publications/freepublications/publication/weo-2016-special-report-energyand-air-pollution.html

41. Conway, D. et al. Climate and southern Africa's water-energy-food nexus. Nat. Clim. Chang. 5, 837-846 (2015).

42. $\quad$ UN Water. UN World Water Development Report 2014: Water and Energy. (2014). Available at: http://unesdoc.unesco.org/images/0022/002257/225741E.pdf

43. FAO. Energy-Smart Food for People and Climate. (2011). Available at: http://www.fao.org/docrep/014/i2454e/i2454e00.pdf

44. Fuso Nerini, F., Andreoni, A., Bauner, D. \& Howells, M. Powering production. The case of the sisal fibre production in the Tanga region, Tanzania. Energy Policy 98, 544-556 (2016).

45. The World Bank. Global Tracking Framework 2017: Progress Towards Sustainable Energy. (World Bank, 2017). Available at: http://www.worldbank.org/en/topic/energy/publication/global-tracking-framework-2017

46. Fuso Nerini, F., Ray, C. \& Boulkaid, Y. The cost of cooking a meal. The case of Nyeri County, Kenya. Envrionmental Res. Lett. 12, 1-15 (2017).

47. Wernberg, T. et al. An extreme climatic event alters marine ecosystem structure in a global biodiversity hotspot. Nat. Clim. Chang. 3, 78-82 (2013).

48. Hoegh-Guldberg, O. et al. Coral Reefs Under Rapid Climate Change and Ocean Acidification. Science (80-. ). 318, 1737 LP-1742 (2007).

49. Sikkema, R. et al. Legal harvesting, sustainable sourcing and cascaded use of wood for bioenergy: Their coverage through existing certification frameworks for sustainable forest management. Forests 5, 2163-2211 (2014).

50. Daw, T., Brown, K., Rosendo, S. \& Pomeroy, R. Applying the ecosystem services concept to poverty alleviation: the need to disaggregate human well-being. Environ. Conserv. 38, 370379 (2011).

51. Terama, E., Milligan, B., Jiménez-Aybar, R., Mace, G. M. \& Ekins, P. Accounting for the environment as an economic asset: global progress and realizing the 2030 Agenda for Sustainable Development. Sustain. Sci. 11, 945-950 (2016).

52. Future Earth. Knowledge-Action Networks | Future Earth. Available at: http://futureearth.org/knowledge-action-networks.

53. IEA and the World Bank. Progress toward sustainable energy 2015. (2015). Available at: http://seforall.org/sites/default/files/GTF-2105-Full-Report.pdf 
For each

Target:
(B) Is there published evidence of synergies or tradeoffs between Target and SDG7?

SDG 7:

Affordable and clean energy

\section{Expert}

elicitation
Targets

1.1 to 17.19

A) Does the Target
call for action in relation to energy systems?

Qualitative

content

analysis

Energy systems at multiple scales

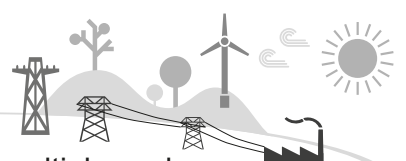

including anthropogenic and environmental components 

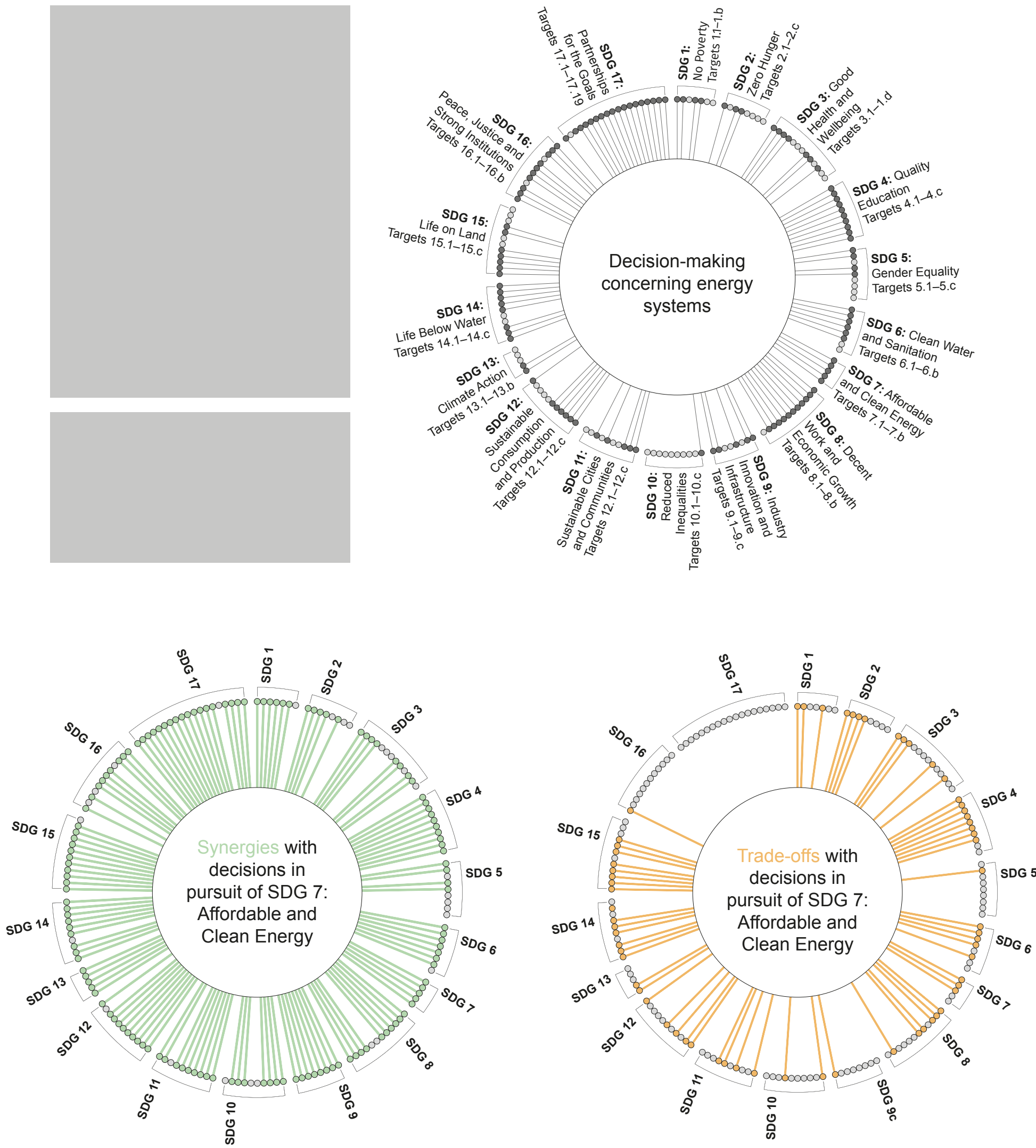